cytoskeletal structures are modified.

\section{P193 自己組織化するリン脂質パターンの位相特異点解析}

3C1205 Phase singularity analysis of self-organizing phosphatidylinositol waves in Dictyostelium discoideum cells

Daisuke Taniguchi ${ }^{1}$, Shuji Ishihara ${ }^{1,2,3}$, Takehiko Oonuki ${ }^{1}$, Kunihiko Kaneko ${ }^{1,2}$, Satoshi Sawai ${ }^{1,2}$ ('Graduate School of Arts and Sciences, University of Tokyo: ${ }^{2}$ Research Center for Complex Systems Biology, University of Tokyo: ${ }^{3}$ PRESTO, JST)

Propagating waves of phosphatidylinositol $(3,4,5)$-trisphosphate $\left(\mathrm{PIP}_{3}\right)$ have recently been reported to be associated with lamellipodial protrusions in Dictyostelium discoideum cells $[1,2]$. However, due to lack of quantitative characterization of the wave geometry, relationship between the waveforms and the ordered pattern of amoeboid shape change [3] remains unclear. We have studied the spatiotemporal patterns of $\mathrm{PIP}_{3}$ at the substrate-attached cell surface by live cell confocal imaging. We observed that $\mathrm{PIP}_{3}$ that self-organizes into persistant or transient spiral and target waves propagate around the cell border and determine timing, direction and shape of membrane protrusions. By extracting phase in the oscillations, we discovered that geometry of wave patterns depends on the dynamics of spontaneous nucleation and topological change in the number of phase singularities. A single phase singularities near the cell boundary support transient spiral waves resulting in rotational membrane protrusions. When actin polymerization is inhibited, these singularities become more stable and support continuous propagation of waves in spiral form. Model simulations suggest that occurance of phase singularities can be tuned by localized production of $\mathrm{PIP}_{3}$ and that coupling with a feedback from F-actin should bias the directionality of chemtaxis.

[1] Y. Asano et al. (2008) Cell. Motil. Cytoskeleton. 65: 923-934

[2] B. S. Diez et al. (2007) HFSP Journal. 3: 412-427

[3] Y. T. Maeda et al. (2008) PLoS ONE. 3: e3734

\section{P194 アメーバ・ケラトモードの転移について}

3C1220 On the amoeba-kerato mode transition

Hirokazu Tanimoto, Masaki Sano, (Department of Physics, Graduate School of Science, the University of Tokyo)

Different cells show different migratory behaviors [1]. Dictyestelium cells and neutrophils move rapidly with changing their shapes, fibroblasts move slowly with also changing their shapes, keratocytes move with keeping their shapes, and neurons extend localized long protrusions. But there may exit underlying physical principles behind this diversity. To study this problem, a experimenta system in which the same cell shows different migratory behaviors is needed. Dictyostelium cell shows both ordinary amoeba motion (amoeba mode) and keratocyte-like motion (kerato mode) when it is cultured without food and at low density. To characterize this model system, we first measured several basic quantities: the switching rate, the velocity vector, the correlation between the velocity and the shape, and so on. Then, we changed the stiffness and adhesiveness of the substrate using agar gels and polyacrylamide gels coating with collagen and measured the same quantities. We also performed the Fourier analysis of the cellular shape dynamics [2].

In the presentation, we will show these results and discuss about the mechanism of amoeba-kerato mode transition with possibly related theoretical works $[3,4]$

\section{References:}

[1] A. Mogilner and K. Keren, Curr. Biol. 19, R762 (2009).

[2] Y. T. Maeda, J. Inose, M. Y. Matsuo, S. Iwaya and M. Sano, PLoS ONE 3(11) e3734 (2008)

[3] M. M. Kozlov and A. Mogilner, Biophys. J. 93, 3811 (2007).

[4] S. I. Nishimura, M. Ueda and M. Sasai, PLoS Comput. BIol. 5(3), e1000310 (2009).

\section{P195 Single-cell level analysis of transcriptional pulses during col-} 3C1235 lective oscillations in Dictyostelium

Noritaka Masaki ${ }^{1}$, Satoshi Sawai ${ }^{1,2},\left({ }^{1}\right.$ Graduate School of Arts andSciences, University of Tokyo ${ }^{2}$ Research Center for Complex Systems Biology)

Studies of mRNA transcription have recently gained a single-cell and singlemolecule resolution. It has become increasingly clear that gene expression is often noisy and heterogeneous - a stochastic process dictated by transition probability of gene on/off states, occurrence of transcriptional pulses and their decay rate. In order to study how time varying inputs regulate these parameters, we analyzed transcriptional pulses of pdsA gene that encodes a key enzyme phosphodiesterase (PDE) required for collective oscillations of cAMP. By visualizing pdsA transcripts as MS2-GFP-RNA complex, we find that, in isolated single cells, basal transcripts can be observed in pulses that appear and disappear in the order of $\sim 3$ minutes. These pulses rarely appear in the absence of extracellular cAMP. Upon continuous application of InM cAMP, spots with a longer lifetime ( $13 \mathrm{~min})$ appear. The percentage of cells showing pulses increases from a few percent to $40 \%$ during the first $10 \mathrm{~min}$ then saturates to $50 \%$ during the next 20 minutes. During collective oscillations of cAMP, we also see that only $\sim 50 \%$ of the cells express pdsA. Transcriptional pulses have a long resting time during the decreasing phase of cAMP indicating that the gene is 'on' or 'off' during the rising and down phase of the oscillations respectively. Interestingly, long lifetime spots appear only during the rising phase of the oscillations. Based on both live cell imaging and RNA-FISH data, we discuss how the observed mode of gene regulation facilitates the onset cAMP waves.

\section{P196複雑系化学物理 XXXV : 異種アメーバ運動における共通性と 差異性の動画像解析}

Complex Chemical Physics XXXV : Study on Commonness and Difference of different kind Amoeboid Locomotion by Motion Image Analysis

Masatoshi Yoshimura ${ }^{1}$, Chihiro Hashimoto ${ }^{2}$, Hideharu Ushiki ${ }^{3},\left({ }^{1}\right.$ Faculty of Agriculture, Tokyo Univ. of Agri. \& Tech.: ${ }^{2}$ Dept. of Appl. Chem. \& Biotech.c Niihama Nat. Coll. of Tech.: ${ }^{3}$ Inst. of Symbiotic Sci. \& Tech., Tokyo Univ. of Agri. \& Tech.)

Amoebas are unicellular protozoans that live in the soil and water. Their movement, called amoeboid locomotion, is considered as the most primitive form of animal locomotion. There are some morphotypes of the shape and movement depending on species, however, the main mechanisms which drive the movement are thought to be same, such as cytoplasmic streaming, actin poly/deploy-merization near cell cortex (sol-gel transition) and the extension/contraction of pseudopodium. The power of this movement is thought to be generated by the slipping movement between the actin filament and the myosin using ATP as energy source. The cell is composed of many kinds of soft matters such as biological macromolecules, and called active soft matter because of its spontaneous movement. The eukaryote such as an amoeba of protozoan moves with large deformation, and shows different morphotype depending on the species. In this work, by analyzing the typical spatio-temporal dynamics of two species of amoeba (Saccamoeba sp. and Mayorella sp.) at room temperature as examples, we will discuss about the commonness and difference in the different kind amoeboid locomotion.

\section{P197 The role of $\mathrm{F}$-BAR protein pacsin 2 in the formation of caveo-} 3C1250 lae

Yosuke Senju, Shiro Suetsugu, (Institute of Molecular and Cellular Biosciences, The University of Tokyo)

Pacsin 2 belongs to the EFC/F-BAR domain protein family and deforms the membrane. The N-terminal F-BAR domain of pacsin2 forms a crescentshaped dimer with a positively charged surface. The F-BAR domaincontaining protein FBP17 plays a function in clathrin-mediated endocytosis; however, the regulation and cellular functions of pacsin 2 have not been examined. Here, we show that pacsin 2 plays a function in caveolae formation.

We performed liposome co-sedimentation assay to investigate the interaction of pacsin 2 with membrane lipids. Both full-length and F-BAR domain of pacsin 2 were coprecipitated with liposomes, indicating that pacsin 2 binds directly to membrane lipids. Next, we observed HeLa cells expressing GFPtagged pacsin2. The cells expressing pacsin 2 F-BAR domain showed inward membrane tubulation, and pacsin 2 colocalized with caveolin-1, but not with clathrin. Therefore, pacsin 2 appeared to interact with caveolin-1. Then, we performed GST pull-down assay to elucidate the interaction of pacsin2 and caveolin- 1 in vitro, and the F-BAR domain of pacsin 2 was coprecipitated with GST-fused N-terminal of caveolin-1. Furthermore, coexpression of full-length pacsin 2 and dynamin- 2 in HeLa cells resulted in a decrease in the plasma membrane tubulation, whereas coexpression with the dominantnegative K44A mutant of dynamin-2 resulted in an increase, indicating that dynamin- 2 pinches off the tubules induced by pacsin 2 . These results suggest that pacsin 2 interacts with caveolin-1 through its F-BAR domain and regulates the formation of caveolae.

3P198 神経細胞膜における GPI アンカー型ラフトタンパク質のプリ オンタンパク質と Thy-1 の異なった局在と拡散運動 : 1 分子イ メジングによる研究

Differential localization and dynamics of raft-associated GPIanchored proteins of prion protein and Thy-1 in the neuronal plasma membrane

Yuri L. Nemoto ${ }^{1,2}$, Chieko Nakada ${ }^{1}$, Hiroko Hijikata ${ }^{1}$, Ankita Chadda ${ }^{1}$, Roger J. Morris ${ }^{3}$, Akihiro Kusumi $^{1},\left({ }^{1}\right.$ Institute for integrated Cell-Material Science (iCeMS), Institute for Frontier Medical Sciences, Kyoto University, Kyoto, 606-8507, Japan: ${ }^{2}$ Research Fellow of the Japan Society for the Promotion of Science: ${ }^{3}$ Wolfson Centre for Age Related Disease, King's College London, SEI IUL, 